\title{
Discrepancy detection and vulnerability to misleading postevent information
}

\author{
JAMES P. TOUSIGNANT, DAVID HALL, and ELIZABETH F. LOFTUS \\ University of Washington, Seattle, Washington
}

\begin{abstract}
When people are exposed to misleading details after a witnessed event, they often claim that they saw the misleading details as part of the event. We refer to this as the misinformation effect. In four experiments, involving 570 subjects, we explored the role that discrepancy detection plays in the misinformation effect. Experiment 1 showed that subjects who naturally read a postevent narrative more slowly were more resistant to the effects of misleading information contained in the narrative. In Experiment 2, subjects who naturally read more slowly were more likely to detect a discrepancy between what they were reading and what was stored in their memory. In Experiment 3, subjects who were instructed to read slowly were more likely to detect a discrepancy than were those who were instructed to read quickly. In Experiment 4, subjects who were instructed to read slowly were more resistant to misleading postevent information. Taken together, these results suggest that longer reading times are associated with a greater scrutiny of postevent information. This leads to an increased likelihood that discrepancies will be detected and that the misinformation will be resisted.
\end{abstract}

In the last few years, a great deal of research has indicated that misleading postevent information can alter a person's recollection of an event (e.g., Bekerian \& Bowers, 1983; Christiaansen, Sweeney, \& Ochalek, 1983; Dodd \& Bradshaw, 1980; Hertel, 1982; Loftus, 1979; Sheehan \& Tilden, 1983; Weinberg, Wadsworth, \& Baron, 1983). We refer to this phenomenon as the misinformation effect. Although research on the misinformation effect is clear in showing that postevent information can influence a person's reported recollection, many questions remain as to why this occurs (Bowers \& Bekerian, 1984; Loftus, Schooler, \& Wagenaar, 1985; McCloskey \& Zaragoza, 1985).

Our current work was motivated, in part, by the observation that exposure to postevent information does not have a uniform influence. That is, not all subjects exposed to misleading information display changes in recollection. For example, in one study (Bekerian \& Bowers, 1983), subjects were exposed to a series of slides of an autopedestrian accident, followed by a single piece of misleading information. If a stop sign was present in the slides, for example, the misleading information implied the existence of a yield sign. In a subsequent randomly ordered test, $40 \%$ of the subjects responded in a way that was commensurate with the misleading information. The remaining $60 \%$ responded correctly, despite the misinformation. Similar results were obtained in another study using different materials (Weinberg et al., 1983): approximately $40 \%$ of the subjects who received misinforma-

\footnotetext{
This work was supported by grants from the National Science Foundation and the National Institute of Mental Health. David Hall, who is at Thiel College, spent a year at the University of Washington with funding from the National Science Foundation and his college. Please address all correspondence to E. Loftus, Department of Psychology, University of Washington, Seattle, WA 98195
}

tion responded in accord with that information, whereas the remaining $60 \%$ responded correctly. What determines whether a subject who is exposed to misinformation will accept or reject that information? Prior studies have shed little light on this question.

In some studies on the misinformation effect, subjects have been exposed to multiple pieces of postevent information (e.g., Greene, Flynn, \& Loftus, 1982; Sheehan $\&$ Tilden, 1983). Vast individual differences in vulnerability have been observed, with some subjects showing consistent acceptance of the intervening information (susceptible subjects) and others showing relatively little or no acceptance of the intervening information (resistant subjects). Thus, in Greene et al. (1982), in which the exposed subjects received four pieces of misleading information, some subjects accepted all four pieces, some three, some two, some one, and some none. Again, a question arises as to why some subjects are susceptible and others are not. Because very few data were collected from individual subjects, beyond simple measures of their final test performance, we know less than we might about the process by which postevent information exerts its influence.

In Greene et al.'s (1982) study, one useful additional measure was taken. Some subjects were warned in advance about the possibility that they would be exposed to misleading information. Subjects who were warned immediately prior to reading the postevent information were more accurate about what they saw then subjects who were not warned at all. Moreover, because all subjects were timed while they read the postevent information, the experimenters observed that the warned subjects read the information more slowly. Greene et al. argued that the warned subjects were reading more slowly and using this extra time to more carefully scrutinize the postevent in- 
formation, which resulted in a greater resistance to its suggestive effect.

Based upon this prior work, we hypothesized that even in the absence of a warning, there would be a relationship between the time subjects take to read and comprehend the postevent message and their ultimate test performance. We expected to find that those who read more quickly would be more influenced by the misleading postevent information. Such a finding would be consistent with the idea that rapid reading minimizes the chances that subjects will detect a discrepancy between what they are reading and what is already in their memory about the event.

Several lines of research on the misinformation effect hint at the important role of discrepancy detection is subjects' resistance to misinformation. Some evidence comes from studies manipulating the intervals of delay between viewing an initial event, encountering a subsequent misleading message, and engaging in a final test of recollection (Loftus, Miller, \& Burns, 1978). These studies show that the number of subjects whose recollection is distorted increases with longer, as opposed to shorter, intervals between an event and subsequent misinformation. Put another way, recollection change appears to be enhanced by the fading of original memory with the passage of time (see also Hertel, Cosden, \& Johnson, 1980; Spiro, 1977).

Another line of work concerns the form of the postevent information. These studies show that recollection is more often affected by the misleading object of an auxiliary clause than by the same misinformation presented in the focus of the question (Loftus, 1981). For example, subjects were more likely to claim that they saw a nonexistent moustache if the moustache was suggested to them via the question "Did the intruder who was tall and had a moustache say anything to the professor?" than if it was suggested to them via the question "Was the moustache worn by the tall intruder light or dark brown?' One explanation for this result is that less attention was given to the misinformation when it was embedded in a minor clause. In this case, misinformation is casually or unintentionally assimilated. When placed at the focus of the question, the misinformation seems to be given more direct and critical attention, and the likelihood of its rejection is enhanced.

One hypothesis that encompasses the effects of warnings, time intervals, and form of postevent information is that the detection of discrepancies between the original memory and the postevent message (or failure to detect discrepancies) is the crucial factor. With a long interval between the event and misinformation, or with misinformation that is subtly embedded, it appears that the ability of subjects to detect a discrepancy between the event information and the postevent information is minimized. Conversely, when subjects are warned about the likelihood of incorrect information, they scrutinize the postevent information, and the likelihood of detection of a discrepancy is enhanced. Thus detection of discrepancies appears to be an important mediating variable, that is, a common underlying factor in the operation of a number of other variables. Unfortunately, prior studies have provided only indirect support for the importance of discrepancy detection. It would be useful to have more direct evidence for this process, and one purpose of the present research was to provide such evidence.

In Experiment 1, subjects first viewed a slide sequence depicting a wallet snatching. Next, they received the postevent information in the form of a narrative that they read under a pretense. Half the subjects received misleading postevent information; the remaining half received neutral information. Reading speed was measured at this time. A short time later several tests were administered to measure susceptibility to the postevent information. Performance on the tests, speed of responding to the critical test items, confidence in responses, and speed of making the confidence judgment were all measured.

We predicted that subjects who were exposed to misleading information would be less accurate than subjects who were not. Of those who received misleading information, we expected that the susceptible subjects would be those who read the information more quickly. Such a result would be consistent with the notion that discrepancy detection is a crucial factor in determining the impact of misleading information.

A word is in order about our purpose in collecting the large set of measures that we did in Experiment 1. We anticipated that such measures-for example, the measure of the speed with which subjects answer test questionsmight provide clues as to the mechanism by which postevent information is incorporated into a person's recollection. One possibility is that misinformed subjects will take longer to respond on the test than do control subjects. This could occur because the subject who sees one object and later "learns" it was a different object has some conflict that needs to be resolved. If the conflict is resolved while the person is responding to a test question, it should take longer to respond following exposure to misleading information than following exposure to neutral information (which presumably does not produce a conflict). On the other hand, misinformed subjects could conceivably respond more quickly on the test items. This would occur if subjects detected a discrepancy while reading the postevent information, and then resolved that discrepancy or conflict prior to the time of the test. Such a result would corroborate an earlier finding obtained using a set of unrelated pictures rather than a coherent event (Cole \& Loftus, 1979).

Experiment 1 provided some preliminary evidence that slower reading times were associated with greater resistance to misinformation. It is tempting to suggest that slower reading maximizes the probability of detecting discrepancies. This was demonstrated more directly in Experiment 2 , a study in which subjects were asked explicitly whether they detected any discrepancies.

A reasonable inference from the first two experiments is that slower reading times lead to discrepancy detection and thus to higher levels of accuracy. However, it is conceivable that causation operates in another way, for ex- 
ample, that susceptibility to misleading information causes the fast reading. Or perhaps susceptible people operate from a bias against careful examination of material that they read. The correlational nature of the data prevent us from excluding this possibility. Therefore, Experiments 3 and 4 were conducted to provide more direct evidence for the hypothesis that slower reading maximizes the probability of detecting discrepancies and results in greater resistance to misleading information. In both studies, subjects saw an event and were then exposed to misleading postevent information. Half the subjects were instructed to read the postevent information as quickly as they could and half were instructed to read it slowly. Finally, in Experiment 3, all subjects were asked whether they detected any discrepancies between what they had read and what they had seen; in Experiment 4, all subjects were tested to ascertain the influence of the postevent misinformation on their performance.

\section{EXPERIMENT 1}

\section{Method}

The procedure involved three major phases: First subjects viewed a set of slides depicting an event, then they were exposed to some new information, and finally they were tested. In the last two phases all presentation and responding were done via an Apple II microcomputer.

\section{Subjects}

The subjects were 180 students at the University of Washington who participated for course credit. They were run in pairs. Two subjects saw the slides together during the first phase, and they were then escorted to separate computers in separate rooms during the remaining phases.

\section{Materials}

Slides. The initial event was a 24-slide series depicting a dramatized wallet-snatching. Each slide was presented for $4 \mathrm{sec}$. The slides show a woman walking down the main street of a small town. She encounters a friend, they talk briefly in front of a store window, and she continues on her way. The woman next sees a man who appears to accidentally bump into her. Her shopping bag falls to the ground, and the two stoop down to pick up the fallen articles. While the woman's back is to him, the man reaches into her shoulder bag and removes her wallet. The woman does not notice, and thanks the man as they part company. After walking a few feet, the woman begins to search her shoulder bag and becomes aware of her missing wallet. At this point, two women standing across the street wave to the victim, approach her, and apparently explain that the "clumsy man" has taken her wallet.

Intervening narrative. There were two versions of the narrative. The misleading version contained seven critical pieces of misleading information, hereafter referred to as the critical items. In addition, there were two more pieces of misleading information that will be discussed separately. Thus, misled subjects received nine pieces of misleading information. The neutral version contained no misinformation. For example, in the slide sequence the victim walks under an overhanging tavern sign. In the misleading narrative, this was referred to as "a restaurant sign overhanging the sidewalk." The neutral narrative referred only to "a sign overhanging the sidewalk." Thus, the misleading version presented inconsistent information; the neutral version presented information that was neither inconsistent nor consistent.

The narratives consisted of 15 sentences written in uppercase lettering. The sentences were presented one at a time on a 12-in. black- and-white monitor. The critical sentences containing either misleading or neutral information were Sentences $3,5,6,7,8$, 9, and 14.

The seven critical items, in order of appearance in the misleading account, suggested that: (1) The victim walked under an overhanging restaurant sign (the actual sign was for a tavern). (2) The victim's friend had short curly black hair (her hair was actually red). (3) A white shirt was displayed in a store window (the shirt was actually yellow). (4) The thief had a light beard and moustache (he actually had only a moustache). (5) The thief knocked both of the victim's bags to the ground (he actually knocked only the shopping bag to the ground). (6) The thief reached with his right hand into the victim's bag (he actually used his left hand). (7) Both witnesses wore brightly colored striped shawls (actually only one witness had a striped shawl). In addition, the misleading version mentioned two items that had not existed at all; a display of shoes in the window, and green vegetables in the victim's shopping bag. The neutral version did not mention these items; the phrases were simply dropped from the narrative.

\section{Apparatus}

The slides were presented by a Kodak 8004 auto-focus carousel slide projector, activated by a repeat cycle timer. Presentation of the narrative and all tests were controlled by an Apple II + microcomputer under the guidance of a program written by $\mathrm{J}$. Tousignant. The monitor was a 12-in. Leedex Video 100 highresolution black-and-white monitor. Response times were measured using a Mountain Hardware clock/calendar card peripheral, located inside the Apple II + . Responses were taken directly from the Apple II + keyboard.

\section{Design and Procedure}

The study was a $2 \times 3$ between-subjects factorial design. Each subject was assigned to one of six groups, according to sign-up time. Independent variables were type of information presented in the narrative (neutral vs. misleading) and the timing of the postevent information. For one third of the subjects, the postevent information and testing occurred immediately after presentation of the slides. For one third of the subjects, a 20-min filler activity intervened between the event and the postevent information; testing followed immediately thereafter. For the remaining one third of the subjects, the postevent information was given immediately after the event, and the $20-\mathrm{min}$ filler activity intervened between the postevent information and testing. In the filler task, subjects were given two Thurber fables, printed on standard ditto paper. For each fable, subjects had to think up an appropriate title and a moral.

After viewing the slides, each subject was escorted into an individual room. Then, depending on the condition to which the subject was assigned, the subject received postevent information from the Apple II + either immediately or after performing the filler task. At the computer, the subject was instructed to read a narrative, ostensibly written by a graduate student. To provide a plausible reason for this activity, the subject was told that the slides were being used in conjunction with a program designed to assess the communication skills of graduate students. He/she was told that a graduate student had viewed the slides and then had written an account of what he saw. The subject was asked to evaluate the writing style of the graduate student. The account was presented one sentence at a time. After reading and comprehending each sentence, the subject pressed the space bar to expose the next sentence. Readingcomprehension time was taken to be the time from the appearance of a sentence on the screen to the time the space bar was pressed. After reading the last sentence, the subject evaluated the account, using a 5-point scale to indicate his/her view of the graduate student's ability to be clear, concise, and understandable.

Test 1, which occurred either immediately or after the 20 -min filler activity, was a two-alternative forced-choice test that asked about various details in the slides. It consisted of $\mathbf{3 0}$ questions, 7 of which pertained to the critical details on which subjects had earlier received misleading or neutral information. An example of a criti- 
cal question was "The victim walked under an...." The subjects were given a choice between two alternative endings: (1) "overhanging tavern sign" and (2) "overhanging restaurant sign." They pressed 1 or 2 to indicate their choice. The endings were counterbalanced, ensuring that each appeared equally often as the first and as the second alternative. The questions that asked about the critical details were Questions 6, 11,13, 19, 23, 27, and 29. Immediately after each question subjects indicated their confidence that their answer was correct. They pressed 1 if they were certain, 2 if they were somewhat certain/somewhat uncertain, and 3 if they were guessing. The questions and confidence measures were presented on the monitor, and answers were taken directly from the keyboard. Reaction times to respond to these test items were obtained. Response time was taken to be the time between the appearance of the test item and the subject's response. Confidence response time was taken to be the interval between the onset of the confidence scale on the monitor and the subject's response.

Test 2 followed Test 1 immediately. The subjects saw 27 descriptive phrases (e.g., "restaurant sign"). For each phrase, they pressed 1 if they had either seen or read about the object described; in other words, if it seemed familiar. They pressed 2 if it did not. Next, the subjects recalled the source of the information. They pressed 1 to indicate that the item had been seen in the slides, 2 to indicate that it had been seen in the narrative, 3 to indicate that it had been seen in the first test, and 4 to indicate that it had never been seen. For example, when presented with the phrase "an overhanging restaurant sign," the subject could respond with 1 , indicating that it was familiar, or 2, indicating that it was not. Following this, the subject might press 1 , then 2 , then 3 , to indicate that the item had been seen in the slides, had been read in the narrative, and also had appeared on the first test. The phrases pertaining to the critical details were Phrases 2, 3, 19, 22, 24, 26, and 27. In addition, the two special items (shoe display and green vegetables) were on this test, as phrases 16 and 21 , respectively. Reaction times taken by subjects to respond to the phrases were obtained.

Upon completion of Test 2, the subjects were thanked for their participation, debriefed, and encouraged to make comments or ask questions about the experiment.

\section{Timing Manipulation}

Recall that our experiment included three different time intervals. Some subjects received their narrative and tests immediately after presentation of the slides, others received the narrative immediately but the tests after a 20-min delay, and still others had a 20-min delay between the slides and the narrative. We expected that misinformation would be more readily accepted if an interval occurred between the event and the postevent narrative. Support for this expectation would be evidenced by a significant interaction between timing interval and type of information on Test 1 or Test 2 . However, no such interaction was found.

The only significant effect attributable to the timing interval manipulation was a main effect for confidence of responding on Test 1 . Subjects were more confident about their answers when a 20-min interval was included than when it was not [no interval, 11.4; interval after slides, 10.4 ; interval after narrative, $10.9 ; F(2,174)=4.63, M S \mathrm{e}$ $=4.28, p<.05]$. (Lower numbers indicate higher confidence, as explained under Secondary Results below.) The timing manipulation had no other significant effects.
Apparently, the 20-min filler activity used in this experiment was not sufficient to produce the retention interval effects we anticipated. In retrospect, we probably should have used longer intervals (e.g., 2 days or so), with which sizable effects were demonstrated in Loftus et al. (1978). In any event, further analyses are collapsed over the timing variable.

\section{Misleading Versus Neutral Postevent Information (Between-Groups Analysis)}

Accuracy on critical test items. On Test 1 seven questions were critical. Table 1 presents the proportion of subjects in error, that is, who selected the misleading alternative, for each of these seven items. Misinformed subjects made more errors than controls ( $44 \%$ vs. $29 \%$ ). On five of the seven critical items, the misled group performed significantly worse than the control group, as revealed by one-tailed tests of significance. The test for overall performance was also significant.

We also analyzed performance on Test 1 by subjects. We assigned a score of 0 to 7 to each subject. A score of 0 indicates that no critical items were answered correctly; that is, the subject answered all critical questions according to the misleading information. A score of 7 indicates that all the critical items were answered correctly; that is, the subject selected only alternatives consistent with the slide sequence. Misinformed subjects received an average score of 3.9 , which did not differ significantly from chance $(3.5)[t(89)=.89, p>.2]$. However, the average score of subjects given neutral information was 4.9 , well above chance $[t(89)=2.80, p<.01]$. The difference between misinformed and control subjects was indeed significant $[F(1,174)=24.05, M S e=2.25$, $p<.01]$.

On Test 2, subjects were tested again on the seven critical details, but in a different way. Test 2 required the subjects to locate the source of familiar items. The percent errors on each of the critical items are shown in Table 2 . We assumed that an error on a critical item occurred when a subject claimed to have seen the item in the slides. Overall, misinformed subjects performed worse than control subjects ( $30 \%$ vs. $23 \%$ errors). Although only two

Table 1

Proportion of Subjects in Error on Test 1 Critical Items

\begin{tabular}{|c|c|c|c|c|c|c|c|}
\hline \multicolumn{8}{|c|}{ Critical Item } \\
\hline Sign & Hair & Shirt & Beard & Bags & Hand & Shawls & Overall \\
\hline \multicolumn{8}{|c|}{ Control Subjects } \\
\hline $\begin{array}{l}.41 \\
(37)\end{array}$ & $\begin{array}{l}.26 \\
(23)\end{array}$ & $\begin{array}{c}.54 \\
(49)\end{array}$ & $\begin{array}{l}.07 \\
(6)\end{array}$ & $\begin{array}{l}.11 \\
(10)\end{array}$ & $\begin{array}{l}.42 \\
(38)\end{array}$ & $\begin{array}{l}.24 \\
(22)\end{array}$ & $\begin{array}{c}.29 \\
(185)\end{array}$ \\
\hline \multicolumn{8}{|c|}{ Misinformed Subjects } \\
\hline $\begin{array}{l}.41 \\
(37)\end{array}$ & $\begin{array}{c}.48 \\
(43)\end{array}$ & $\begin{array}{c}.74 \\
(67)\end{array}$ & $\begin{array}{r}.33 \\
(30)\end{array}$ & $\begin{array}{c}.27 \\
(24)\end{array}$ & $\begin{array}{c}.49 \\
(44)\end{array}$ & $\begin{array}{r}.38 \\
(34)\end{array}$ & $\begin{array}{c}.44 \\
(279)\end{array}$ \\
\hline \multicolumn{8}{|c|}{$t$-Test Results } \\
\hline 0.0 & $3.06 *$ & $2.78 *$ & $4.36^{*}$ & $2.74^{*}$ & .94 & $2.03 \dagger$ & $5.51^{*}$ \\
\hline
\end{tabular}

Note-Numbers in parentheses are number of subjects in error for each item. ${ }^{*} p<.01 . \quad \dagger p<.05$. 
Table 2

Proportion of Subjects in Error on Test 2 Critical Items

\begin{tabular}{|c|c|c|c|c|c|c|c|}
\hline \multicolumn{8}{|c|}{ Critical Item } \\
\hline Sign & Hair & Shirt & Beard & Bags & Hand & Shawls & Overal \\
\hline \multicolumn{8}{|c|}{ Control Subjects } \\
\hline $\begin{array}{c}.31 \\
(28)\end{array}$ & $\begin{array}{c}.23 \\
(21)\end{array}$ & $\begin{array}{l}.30 \\
(27)\end{array}$ & $\begin{array}{l}.03 \\
\text { (3) }\end{array}$ & $\begin{array}{l}.26 \\
(23)\end{array}$ & $\begin{array}{c}33 \\
(30)\end{array}$ & $\begin{array}{l}.13 \\
\text { (12) }\end{array}$ & $\begin{array}{c}.23 \\
(144)\end{array}$ \\
\hline \multicolumn{8}{|c|}{ Misinformed Subjects } \\
\hline $\begin{array}{c}.32 \\
(29)\end{array}$ & $\begin{array}{r}.37 \\
\text { (33) }\end{array}$ & $\begin{array}{l}.40 \\
(36)\end{array}$ & $\begin{array}{c}.21 \\
(19)\end{array}$ & $\begin{array}{c}.21 \\
(19)\end{array}$ & $\begin{array}{c}.38 \\
(34)\end{array}$ & $\begin{array}{r}.20 \\
(18)\end{array}$ & $\begin{array}{r}.30 \\
(188)\end{array}$ \\
\hline \multicolumn{8}{|c|}{$t$-Test Results } \\
\hline .16 & $1.96 \dagger$ & 1.41 & $3.65^{*}$ & -.71 & .63 & 1.21 & $2.78^{*}$ \\
\hline
\end{tabular}

Note-Numbers in parentheses are number of subjects in error for each item. ${ }^{*} p<.01 . \quad t p<.05$

of the seven critical items reached individual levels of statistical significance, the overall difference was significant.

We also analyzed performance on Test 2 by subjects. Misinformed subjects claimed to have seen in the slides an average of 2.1 items, whereas control subjects claimed to have seen an average of 1.6 items $[F(1,174)=6.1$, $M S e=2.01, p<.025]$. Thus, the misinformed group made more errors than the control group on the Test 2 critical items, whether the analysis was conducted by subjects or by items.

In addition to the seven critical details, two special items tested two pieces of information on which the subjects had not been tested previously. When asked on Test 2 about a shoe display, which was never seen but was mentioned as an item of misinformation, $24 \%$ of the misinformed subjects recalled having seen the display in the slide sequence. Only $8 \%$ of the control subjects claimed to have seen the nonexistent shoe display in the slides. When asked about green vegetables, which had been mentioned in the misleading but not the neutral narrative, $32 \%$ of the misinformed subjects claimed to have seen green vegetables in the slide sequence. Only $8 \%$ of the control subjects claimed to have seen the green vegetables. These two items provide additional support for the susceptibility of individuals to misleading postevent information.

Speed of reading the postevent narrative. Analysis of reading times revealed that subjects who were exposed to misinformation took significantly longer to read the narrative, averaging $9.5 \mathrm{sec}$ per critical sequence, than did the control group $(7.4 \mathrm{sec})[F(1,174)=18.96, M S \mathrm{Se}=$ $10.44, p<.01]$. In evaluating this result, it should be kept in mind that the critical narrative sentences were not equated for length. That is, when misinformation was added to the narrative, the critical sentences became slightly longer. In fact, the average length of the critical sentences in the misleading narrative was 21.0 words, whereas in the neutral narrative it was 18.1 words. To adjust the reading rates, proportions were constructed by taking the average reading time for each group and dividing it by the mean sentence length. This resulted in proportional rates of .45 for the misinformed subjects and .41 for the control subjects. Although these rates still indi- cate slightly longer reading times for the misinformed subjects, the difference is no longer significant $[t(178)=.71$, $p>.10]$.

Secondary results. Several other results, although not germane to the discussion of discrepancy detection, are worth reporting. On the filler (noncritical) items of Test 1 , subjects who received misinformation were as accurate as controls (75\% vs. $73 \%$ correct). Some of the filler items pertained to details that had been seen in the slides and mentioned in the postevent narrative; other filler items pertained to details that had appeared only in the slides. The misinformed subjects performed as well as the control subjects on both the first and second types of items $[F(1,174)$ $=1.55$ and $F(1,174)=.89$, respectively]. This suggests that the two groups did not differ in terms of general ability to perceive and recall details. More importantly, it suggests that the misinformed subjects did not adopt a strategy of rejecting as inaccurate other information recalled from the narrative. If they had adopted this strategy, they would have performed poorly on the first type of filler item for which accurate postevent information had been given.

Misinformed subjects were more confident about their responses on the critical items. For purposes of analysis, we assigned to each subject a score that reflected reported confidence on the critical items ( 1 = "certain"). The scores ranged from 7 to 21 , and were obtained by summing the confidence ratings for the seven critical items. We found that misinformed subjects' average summed confidence was 10.3 , whereas control subjects' average confidence was $11.5[F(1,174)=14.3, M S e=4.28$, $p<.01]$. Lower numbers indicate higher confidence.

It is important to examine the confidence scores separately for correct and incorrect responses, and this is shown in Table 3 . As can be seen, when they answered correctly, misinformed and control subjects did not differ greatly in their confidence estimates. For correct responses, the misinformed subjects' average confidence per item was 1.44 , whereas the control subjects' average

Table 3

Mean Test 1 Confidence Estimations by Accuracy Confidence on Test 1

\begin{tabular}{cccccccc}
\hline Sign & Hair & Shirt & Beard & Bags & Hand & Shawls & Overall \\
\hline \multicolumn{7}{c}{ Accurate } \\
Control Subjects \\
1.32 & 1.39 & 2.17 & 1.26 & 1.09 & 1.62 & 2.10 & 1.51 \\
$(53)$ & $(67)$ & $(41)$ & $(84)$ & $(80)$ & $(52)$ & $(68)$ & $(445)$ \\
\multicolumn{7}{c}{ Misinformed Subjects } \\
1.19 & 1.40 & 2.04 & 1.35 & 1.09 & 1.48 & 1.93 & 1.44 \\
$(53)$ & $(47)$ & $(23)$ & $(60)$ & $(66)$ & $(46)$ & $(56)$ & $(351)$ \\
& \multicolumn{7}{c}{ Inaccurate } \\
\multicolumn{7}{c}{ Control Subjects } \\
$(37)$ & 1.61 & 2.37 & 1.83 & 1.00 & 1.60 & 2.04 & 1.95 \\
& $(23)$ & $(49)$ & $(6)$ & $(10)$ & $(38)$ & $(22)$ & $(185)$ \\
1.68 & 1.39 & 1.54 & 1.43 & 1.17 & 1.45 & 1.88 & 1.52 \\
$(37)$ & $(43)$ & $(67)$ & $(30)$ & $(24)$ & $(44)$ & $(34)$ & $(279)$ \\
\hline
\end{tabular}

Note-Numbers in parentheses are number of subjects. Lower numbers indicate higher confidence. 
confidence was 1.51. However, when they selected the incorrect responses (corresponding to the misleading details), the misinformed subjects expressed substantially more confidence than controls (1.52 vs. 1.95).

Misinformed subjects were faster than control subjects in speed of responding to critical items. Specifically, misinformed subjects took less time than controls to respond on Test $2[5.1 \mathrm{sec}$ vs. $6.2 \mathrm{sec}, F(1,174)=6.89, M S \mathrm{e}=$ $7.97, p<.01]$. The misinformed subjects also responded somewhat faster on Test $1(7.4 \mathrm{sec}$ vs. $7.6 \mathrm{sec})$, although this difference was not statistically significant $(p>.25)$.

\section{Individual Differences Among the Misinformed (Within-Group Analysis)}

Using only the data from the 90 subjects who were treated to misleading postevent information, we next looked for characteristics that might differentiate subjects who were highly susceptible from those who were not.

Test 1 performance. Recall that we assigned to each subject a score ranging from a low of 0 to a high of 7 to indicate the number of correct responses on the critical items. Figure 1 shows the distribution of scores for the misinformed subjects. (For comparison, the response distribution for the control group is also shown.) An examination of this figure reveals that the distribution is not bimodal, as might have been expected, with some misinformed subjects being very susceptible and others very resistant. Rather, subjects accepted varying amounts of misinformation. Scores of $3,4,5$, or 6 correct were common, which means from one to four responses were incorrect (i.e., corresponded to the misinformation).

Cutting this distribution at the median allowed us to compare the susceptible subjects (those scoring below the median) to the resistant subjects (those scoring above the median). Obviously, by definition, the two groups differed in performance on the critical items. But would they also differ in terms of performance on the filler items? In fact, the two groups performed differently on one class of filler items, namely, the items that were mentioned in both the slides and the narrative $[t(44)=2.97, p<.01]$. The susceptible subjects averaged 6.2 items correct, compared to 7.0 items for the resistant subjects. However, on filler items that were seen only in the slides, the two groups

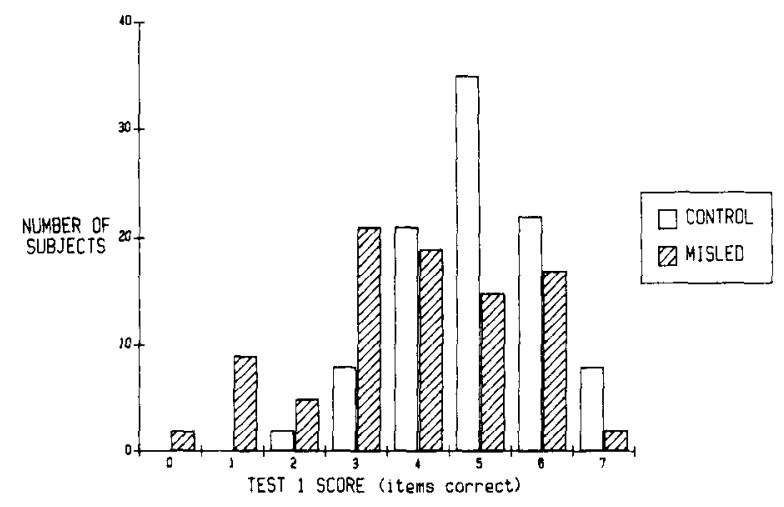

Figure 1. Test 1 response distribution.

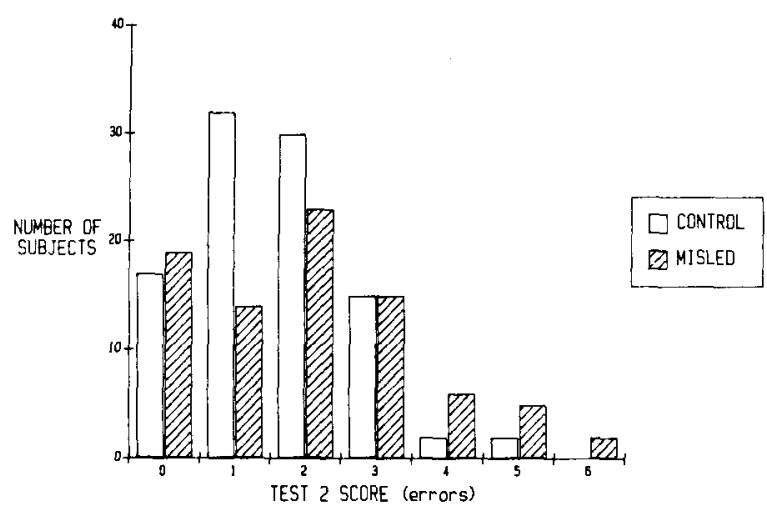

Figure 2. Test 2 response distribution.

did not differ $[t(44)=.46, p>.2]$. This suggests that the susceptible subjects may not have processed the information in the postevent account as well as did the resistant subjects. However, they were just as capable of viewing and recalling filler details from the slides.

To assess other relationships with Test 1 performance, we correlated Test 1 scores with the time taken to read the postevent narrative, with the time taken to respond on Test 1 , and with confidence scores. We expected to observe a relationship between the narrative reading times and susceptibility to being misled; however, this expectation was not confirmed. The simple correlation was .10, indicating that slow reading was associated with more correct answers; however, the correlation was not significant $[F(1,84)<1.0]$.

The correlation between Test 1 performance and speed of responding to the items was -.07 , and was not significant $[F(1,84)<1]$. The only measure found to account for a significant percentage of the variability in Test 1 performance was average confidence $[r=.18$; $F(1,84)=4.23, M S e=2.79, p<.05]$. This correlation indicates that subjects who show a higher degree of susceptibility also show a tendency to be confident about their responses.

Test 2 performance. Recall that on Test 2 subjects were asked to indicate whether they had seen the critical details in the slides, in the narrative, on the first test, or not at all. The number of critical (nonexistent) items that were recalled as having occurred in the slides could range from 0 to 7 . Actual scores ranged from 0 to 6 . Figure 2 shows the distribution of responses. (For comparison, the response distribution for the control group is also shown.) The modal number (and median) of critical items recalled by misinformed subjects as having been in the slides is 2 .

Once again, cutting at the median, we assessed performance differences between the susceptible and resistant subjects on filler items. No significant differences were found in performance, either on filler items that could be answered based on information from the slides alone $[t(44)=1.29, p>.1]$ or on filler items that could be answered based on information from the slides and narrative $[t(44)=.59, p>.2]$. 
A second regression was run to assess other relationships with Test 2 performance. This time, a significant correlation was found between performance on Test 2 and the time subjects had taken to read the postevent narrative $[F(1,84)=4.76, M S \mathrm{e}=2.39, p<.05]$. The simple correlation was -.25 , indicating that the faster subjects read the narrative, the greater number of errors they made on Test 2. For example, subjects who were incorrect on five critical items had taken an average of $7.6 \mathrm{sec}$ per critical sentence to read the narrative; subjects who were incorrect on only one critical item had taken an average of $10.1 \mathrm{sec}$.

Speed of responding on Test 2 was uncorrelated with Test 2 performance $(r=.03)$. Confidence on Test 2 and accuracy were only marginally related, with subjects who were susceptible to postevent information reporting somewhat higher levels of confidence $[F(1,84)=3.14, M S \mathrm{e}$ $=2.56, p<.10]$.

Comparison of Test 1 to Test 2. One final analysis concerns the relationship between the two tests. This is shown in Table 4 . The left portion of the table shows performance on Test 2, blocked by performance on Test 1 . The right portion of the table shows performance on Test 1 , blocked by Test 2 performance. The association between these measures is significant $(r=-.53$, $p<.001$ ), indicating that $28 \%$ of the variance of the two measures of susceptibility is shared variance. The simple correlations between Test 1 and Test 2 performance were also significant, both when taken over all 180 subjects $(r=-.48, p<.001)$ and for the 90 control subjects $(r=-.30, p<.01)$.

Although performance on Test 1 and Test 2 is obviously related, the question arises whether the two tests measured the same thing. From a comparison of Test 1 and Test 2 , it is clear that many more subjects were willing to select the misleading alternative on a test of memory for the original event than were willing to state, when explicitly asked to indicate whether they remembered the information from the slides, narrative, or first test, that they saw the misleading information in the slides. One possible explanation for this discrepancy is that during Test 2 subjects could indicate that they remembered a critical detail from the first test. Since the appearance of the

Table 4

Relationship Between Number Correct on Test 1 and Number of Errors on Test 2

\begin{tabular}{cccc}
\hline Test 1 Score & Test 2 Mean & Test 2 Score & Test 1 Mean \\
\hline 0 & 3.00 & 0 & 4.79 \\
1 & 2.78 & 1 & 4.43 \\
2 & 2.60 & 2 & 4.17 \\
3 & 3.00 & 3 & 3.67 \\
4 & 2.05 & 4 & 2.92 \\
5 & 1.33 & 5 & 1.80 \\
6 & 1.06 & 6 & 0.50 \\
7 & 0.00 & &
\end{tabular}

Note-Left portion shows the mean score for subjects on Test 2 as a function of score on Test 1; right portion shows the mean score for subjects on Test 1 as a function of score on Test 2 . detail on the first test would have been quite recent, this source may have been strongest in subjects' recollections. Any "recollection" from the relatively earlier event itself would, by contrast, seem weaker, and the tendency to indicate that the item was in the slides would thereby be reduced. This is a speculation that must be addressed in future research aimed at determining how susceptibility to misinformation should be defined.

\section{Discussion}

In reiterating the major results to emerge from Experiment 1 , we first note the overall differences found in accuracy between subjects exposed to misleading postevent information and control subjects. We expected, and found, misinformed subjects to be significantly less accurate. We also found that, overall, misinformed subjects reported higher levels of confidence in their incorrect responses than did control subjects. Furthermore, misinformed subjects did not take longer than controls to respond on test items. If anything, they took less time. This suggests that the subjects were not resolving conflicts between their original memory and the postevent information while they were taking the test.

The second set of analyses was conducted on the misinformed group alone. As anticipated, we found that subjects who were exposed to misleading information varied in the extent to which they accepted it and incorporated it into their recollection. Subjects showing high susceptibility reported higher levels of confidence, particularly when they were incorrect. Susceptible subjects responded at least as quickly on test items as subjects who were resistant. This suggests that resistance to misinformation does not come about because of slower, more deliberate, or more careful test-taking.

Of major interest is the finding that the susceptible subjects read the postevent narrative more quickly than did the resistant subjects. This was most clearly shown by performance on Test 2 . On Test 1 , subjects who read slowly tended to perform better, but the correlation was not significant. We have no explanation for why the relationship between reading times and test performance was stronger in one analysis than in the other. Subsequent experiments, using much simpler designs, were successful in painting a clearer picture of the relationship between reading speed and discrepancy detection.

\section{EXPERIMENT 2}

We have suggested that the slower reading times of the resistant subjects indicate that these subjects were more carefully scrutinizing the postevent narrative. This scrutiny would enhance the likelihood of subjects' detecting discrepancies between what they read and what was stored in their memory. Our inference regarding discrepancy detection can be tested in a more direct fashion. If we were to take subjects who had just finished reading the postevent narrative and ask them directly about discrepancies, 
would slower readers be more likely to reveal that they had noticed discrepancies? Experiment 2 was designed to answer this question.

\section{Method}

This experiment involved three major phases. First the subjects viewed a set of slides depicting a wallet-snatching incident. Next, all subjects read a misleading narrative. Finally, they were asked directly whether they detected any discrepancies between what they had read and what they remembered seeing.

The subjects were 120 students at the University of Washington who participated for course credit. They saw the same 24-slide sequence used in Experiment 1, presented at a rate of $4 \mathrm{sec}$ per slide. Next they read a narrative, ostensibly written by a graduate student, and evaluated the writing style. The narrative was identical to the neutral narrative used in Experiment 1, except that it contained one misleading item. It referred to the short curly black hair of the victim's friend (actually, the hair was red). This misinformation was contained in Sentence 5 of the 15 -sentence narrative. Subjects were timed while they read the narrative. Timing was accomplished by instructing the subjects to press the space bar after reading each sentence, in order to expose the next sentence. Reading comprehension time was taken to be the time from the appearance of a sentence on the screen to the subject's pressing of the space bar.

After reading the last sentence, the subjects evaluated the writing style. Then each subject was asked only one question by the experimenter: "Did you notice any discrepancies between what you just read on the computer screen and what you saw before in the slides?"' The experimenter pretended to take notes, but actually only recorded whether the subject explicitly mentioned the discrepancy concerning the hair color of the victim's friend. After this, the subjects were debriefed and thanked for their participation.

\section{Results}

The subjects were divided into two groups (slow and fast readers), according to the time they spent reading the narrative. This was accomplished by simply splitting subjects at the median reading time. This split resulted in a median reading time of $10.4 \mathrm{sec}$ per sentence for the slow readers and $7.8 \mathrm{sec}$ per sentence for the fast readers. Among the 60 slow readers, $12 \%$ explicitly mentioned the discrepancy regarding the hair color of the victim's friend. Among the 60 fast readers, only $2 \%$ (1 subject) explicitly mentioned the discrepancy. This difference is significant by a $z$ test for proportions $(z=2.15, p<.05)$.

\section{Discussion}

This experiment provided direct evidence for the proposition that subjects who read postevent information more slowly are more likely to detect discrepancies between what they are reading and what is in their memory. We have suggested that slower reading is associated with greater scrutiny, and this leads to greater accuracy. However, the correlational nature of this result prevents us from ruling out the possibility that there is another cause for the observed relationship. Perhaps people who are susceptible to postevent information operate from a bias against careful examination of material. To gather data that would assist in disentangling these possibilities, we conducted Experiment 3.

\section{EXPERIMENT 3}

\section{Method}

This experiment was similar to Experiment 2, with one exception. Ninety subjects were shown the wallet-snatching slides at a rate of $4 \mathrm{sec}$ per slide. Next all subjects read the narrative used in Experiment 2, containing the single item of misinformation regarding the hair of the victim's friend. Half of the subjects were instructed to read the narrative as quickly as possible, whereas the other half were instructed to read it slowly. The subjects evaluated the writing style, and were then asked whether they had noticed any discrepancies between what they had read and what they had seen.

\section{Results}

The subjects were divided into two groups (slow and fast readers), according to whether they had been instructed to read slowly or quickly. The slow readers' median reading time was $10.8 \mathrm{sec}$ per sentence; the fast readers' median time was $7.5 \mathrm{sec}$ per sentence. None of the fast readers mentioned the discrepancy in the description of the victim's friend's hair. However, $11 \%$ of the slow readers mentioned the discrepancy $(z=2.29$, $p<.05$ ). Thus, the instruction to read slowly led directly to greater discrepancy detection.

\section{Discussion}

Slower reading led to greater discrepancy detection. One possible explanation for this finding is that subjects who were instructed to read as quickly as they could may not have detected the discrepancy because they were reading so quickly that they never encoded the misleading information. One piece of evidence that argues against this possibility is that the reading times of subjects who were instructed to read quickly in Experiment 3 were comparable to those of subjects in Experiment 2 who naturally read quickly ( $7.5 \mathrm{sec}$ per sentence vs. $7.8 \mathrm{sec}$ per sentence, $t<1$ ). Converging evidence for the notion that slower reading encourages discrepancy detection, which leads to better test performance, could be found in a study that included a direct measure of test performance; therefore, we conducted Experiment 4.

\section{EXPERIMENT 4}

\section{Method}

This experiment was similar to Experiment 3, with one exception. One hundred eighty subjects were shown the wallet-snatching slides at a rate of $4 \mathrm{sec}$ per slide. Next they performed a 10-min unrelated filler task, and then all subjects read the narrative used in the previous study, containing the single item of misinformation regarding the hair of the victim's friend. Half of the subjects were instructed to read the narrative as quickly as possible, whereas the other half were instructed to read it slowly. The subjects were asked to evaluate the writing style of the narrative.

Finally, the subjects were tested on a five-item test. The first four items were filler items that were based only on information from the slides. The fifth was the critical item regarding the hair color. The critical item was a two-alternative forced-choice item: the subjects were to indicate whether they had seen short curly black hair 
or red hair on the victim's friend. The order of the two answers was counterbalanced across subjects.

\section{Results}

We inadvertently failed to collect reading rates in this study. However, since the subjects were treated exactly as in Experiment 3, we can assume that those instructed to read slowly did read more slowly than those who were instructed to read quickly. In terms of performance, the subjects who were instructed to read the postevent narrative slowly were more likely to be correct on the critical items than were subjects who were instructed to read quickly $(63 \%$ vs. $48 \%$ correct; $z=2.16, p<.05$ ). On the four filler items, the subjects who received misinformation performed as well as did the control subjects ( $82 \%$ vs. $81 \%$ correct). This suggests that the two groups did not differ in terms of general ability to perceive and recall details.

\section{GENERAL DISCUSSION}

Our first experiment showed that subjects who naturally read a postevent narrative more slowly were more resistant to the effects of misleading information, at least on one of the two tests that were given. In Experiment 2, we demonstrated that subjects who naturally read more slowly were more likely to detect a discrepancy between what they were reading and what was stored in their memory. In Experiment 3, we demonstrated that when subjects were instructed to read slowly, they were more likely to detect a discrepancy. Finally, in Experiment 4, we showed that subjects who were instructed to read slowly were more accurate on a subsequent test.

Taken together, these results suggest that longer reading times are associated with greater scrutiny of postevent information. This scrutiny leads to an increased likelihood that discrepancies will be detected and that the misinformation will be resisted. The notion of detection of discrepancies can help us to understand, and even predict in advance, the likely influence of a number of situational and individual difference variables that could potentially lead to a misinformation effect. Some of these variables were identified earlier. There are many others. For example, Sheehan, Grigg, and McCann (1984) discovered that hypnotic subjects were more likely to incorporate misleading material into their memories than were their nonhypnotized counterparts. They discussed this finding in terms of the hypothesis that hypnosis lowers the level of subjects' cognitive scrutiny of the postevent information that is presented. When the level of scrutiny of incorrect information is lowered, resistance to the influence of misleading information can be expected to be less. Independent evidence also suggests that hypnotized people process events distinctively and are less critical of the communications they receive than are nonhypnotized people (Sheehan \& McConkey, 1982).

We do not believe that the relationship between attention paid to postevent information and the ability to resist that information would necessarily be linear when the full span of attention is considered. Rather, the relationship is likely to be curvilinear, for this reason: Consider 3 subjects who are equal in ability and susceptibility, but who differ in the amount of attention each gives to postevent information. If Subject 1 pays little or no attention to the information, the likelihood that it would be encoded would be low. Consequently, the probability that the misinformation would influence recall would also be low. If Subject 2 critically attends to the information, it is likely that this scrutiny would lead to enhanced probability of detection and subsequent rejection of misinformation. In this case, the probability that the misinformation would detrimentally affect recall would be relatively low. If Subject 3 devotes a moderate amount of attention to the misinformation, he or she may exhibit the greatest degree of influence on reported memory. What is needed is sufficient attention that the misinformation is encoded in memory, but not so much that the subject consciously detects the discrepancies.

In sum, this discussion emphasizes the role that detection of discrepancies plays in the likelihood that a person is influenced by postevent information. We suggest that alterations in recollection are more likely to occur if a person does not consciously notice such discrepancies. It is reasonable at this point to propose that the likelihood of detecting discrepancies is a function of the amount of attention devoted to the misinformation. With careful and deliberate attention, the likelihood of detecting inconsistencies or discrepancies is enhanced. One principle governing the alteration of recollections, then, is this: Recollections are more likely to change if a person does not immediately detect discrepancies between postevent information and memory for the original event. The current research provides the first direct support for this principle.

\section{REFERENCES}

Bekerian, D. A., \& Bowers, J. M. (1983). Eyewitness testimony: Were we misled? Joumal of Experimental Psychology: Leaming, Memory, \& Cognition, 9, 139-145

Bowers, J. M., \& Bekerian, D. A. (1984). When will post-event information distort eyewitness testimony? Journal of Applied Psychology, 69, 466-472.

Christianansen, R. E., Sweeney, J. D., Ochalek, K. (1983). Influencing eyewitness descriptions. Law \& Human Behavior, 7, 59-65

COLE, W. G., LofTUS, E. F. (1979). Incorporating new information into memory. American Journal of Psychology, 92, 413-425.

DodD, D. H., B BaDShaW, J. M. (1980). Leading questions and memory: Pragmatic constraints. Journal of Verbal Learning \& Verbal Behavior, 19, 695-704

GreEne, E., FlynN, M. S., \& Loftus, E. F. (1982). Inducing resistance to misleading information. Journal of Verbal Learning \& Verbal Behavior, 21, 207-219.

HerTel, P. T. (1982). Remembering reactions and facts: The influence of subsequent information. Joumal of Experimental Psychology: Leaming, Memory, \& Cognition, 8, 513-529.

HeRTEL, P. T., Cosden, M., Johnson, P. J. (1980). Passage recall: Schema change and cognitive flexibility. Joumal of Educational Psychology, 72, 133-140.

LofTus, E. F. (1979). Eyewitness testimony. Cambridge, MA: Harvard University Press. 
LoFTUS, E. F. (1981). Mentalmorphosis: Alterations in memory produced by mental bonding of new information to old. In J. Long \& A. Baddeley (Eds.), Attention and performance IX (pp. 417-434) Hillsdale, NJ: Erlbaum.

LofTus, E. F., Miller, D. G., \& BuRNs, H. J. (1978). Semantic integration of verbal information into visual memory. Journal of $E x$ perimental Psychology: Human Learning \& Memory, 4, 19-31.

Loftus, E. F., Schooler, J. W., \& WagenaAR, W. A. (1985). The fate of memory: Comment. Journal of Experimental Psychology: General, 114, 375-380.

MCCloskeY, M., \& ZaragozA, M. (1985). Misleading postevent information and memory for events: Arguments and evidence against memory impairment hypotheses. Journal of Experimental Psychology: General, 114, 1-16.

Sheehan, P. W., Grigg, L., \& McCanN, T. (1984). Memory distortion following exposure to false information in hypnosis. Journal of Abnormal Psychology, 93, 259-265.
Sherhan, P. W., \& McConkey, K. M. (1982). Hypnosis and experience: The exploration of phenomena and process. Hillsdale, $\mathrm{NJ}$ : Erlbaum.

SheEhan, P., \& Tilden, J. (1983). Effects of suggestibility and hypnosis on accurate and distorted retrieval from memory. Journal of Experimental Psychology: Learning, Memory, \& Cognition, 9, 283-293.

SPIRo, R. J. (1977), Constructing a theory of reconstructive memory: The state of schema approach. In R. C. Anderson, R. J. Spiro, \& W. E. Montague (Eds.), Schooling and the acquisition of knowledge. Hillsdale, NJ: Erlbaum.

Weinberg, H. I., Wadsworth, J., \& Baron, R. S. (1983). Demand and the impact of leading questions on eyewitness testimony. Memory \& Cognition, 11, 101-104.

(Manuscript received May 10, 1985; revision accepted for publication January 6,1986 . 